\title{
Validation of MRI quantification of biventricular cardiac function in term and preterm neonates
}

\author{
Anna Finnemore*, Anthony N Price, Giuliana Durighel, Kathryn Broadhouse, David J Cox, Alan Groves \\ From 16th Annual SCMR Scientific Sessions \\ San Francisco, CA, USA. 31 January - 3 February 2013
}

\section{Background}

Accurate measurement of neonatal cardiac function remains a key goal to improve understanding of circulatory pathophysiology in prematurity. Cardiac MRI has been shown to be viable in this population, but robust validation is crucial.

Our aim was to assess the accuracy of cardiac functional measures derived from MRI ventricular stack segmentation against phase contrast measures in term and preterm neonates.

\section{Methods}

Cardiac MRI scans were performed on a 3T Philips Achieva scanner (Best, Netherlands) in 40 infants (gestational age $24+3-40+2$ weeks/ weight at scan $750-3120 \mathrm{~g}$ ). Left ventricular stacks were segmented for epicardial and endocardial contours at end systole and end diastole using Segment software (http://segment.heiberg.se) with manual correction of segmentation where necessary. Correction for long axis motion was performed using the mean of three measures of atrio-ventricular valve descent from a 4 chamber view. Right ventricular stacks were segmented for endocardial contours on 20 infants (gestational age $24+3-40+2$ weeks/ weight at scan $790-$ $3120 \mathrm{~g})$ using the same technique. Cardiac output (CO) was measured by semi-automatic segmentation (View Forum,Philips) of phase contrast(PC) images of the left ventricular outflow tract. The two techniques were com- pared using a Bland Altman plot. Infants with known patent ductus arteriosus were excluded.

\section{Results}

Bland Altman analysis of left ventricular output by stack and PC showed a mean bias of $14.2 \mathrm{ml} / \mathrm{min}$, with limits of agreement of -54.8 to $83.2 \mathrm{ml} / \mathrm{min}$,, corresponding to a repeatability index (RI, limits of agreement/mean of population) of $16.6 \%$. Bland Altman analysis of right ventricular output by stack and left ventricular output by PC showed a mean bias of $39.7 \mathrm{ml} / \mathrm{min}$, with limits of agreement of -36.9 to $116.5 \mathrm{ml} / \mathrm{min}$ corresponding to a repeatability index (RI) of $17.3 \%$. For comparison Bland Altman of neonatal heart rate during by stack and PC imaging showed a mean bias of -2.12 beats $/ \mathrm{min}$, with limits of agreement of -19.21 to 14.96 beats/min, corresponding to a repeatability index (RI) of $11.92 \%$.

\section{Conclusions}

Given the wide variability of heart rates and potential for motion in preterm neonatal scanning, our findings suggest stack segmentation at our improved resolution can give relatively accurate measures of preterm cardiac function.

\section{Funding}

Dr Finnemore is a British Heart Foundation Clinical Training Fellow. 

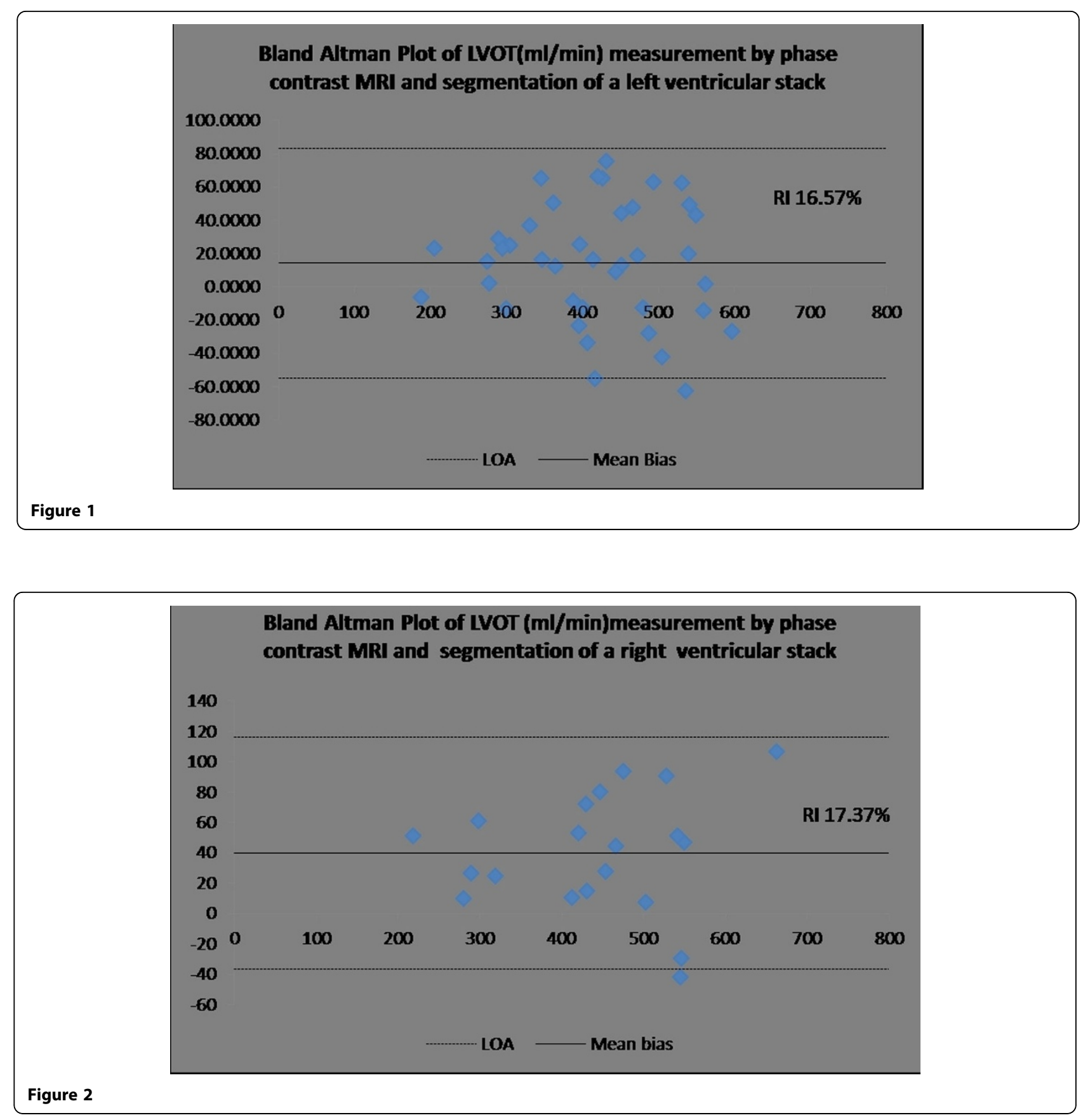

doi:10.1186/1532-429X-15-S1-P294

Cite this article as: Finnemore et al:: Validation of MRI quantification of biventricular cardiac function in term and preterm neonates. Journal of Cardiovascular Magnetic Resonance 2013 15(Suppl 1):P294.
Submit your next manuscript to BioMed Central and take full advantage of:

- Convenient online submission

- Thorough peer review

- No space constraints or color figure charges

- Immediate publication on acceptance

- Inclusion in PubMed, CAS, Scopus and Google Scholar

- Research which is freely available for redistribution

Submit your manuscript at www.biomedcentral.com/submit
C BioMed Central 